\title{
European eel restocking programs based on wild-caught glass eels: Feasibility of quarantine stage compatible with implementation of prophylactic measures prior to scheduled reintroduction to the wild
}

\author{
Natacha Delrez ${ }^{\mathrm{a}}$, Haiyan Zhang ${ }^{\mathrm{a}}$, François Lieffrig ${ }^{\mathrm{b}}$, Charles Mélard ${ }^{\mathrm{c}}$, Frédéric Farnir ${ }^{\mathrm{d}}$, \\ Maxime Boutier ${ }^{\mathrm{a}}$, Owen Donohoe ${ }^{\mathrm{a}, \mathrm{e}}$, Alain Vanderplasschen ${ }^{\mathrm{a}, *}$ \\ ${ }^{a}$ Immunology-Vaccinology, Department of Infectious and Parasitic Diseases, Fundamental and Applied Research for Animals \& Health (FARAH), Faculty of Veterinary \\ Medicine, University of Liège, Liège, Belgium \\ ${ }^{\mathrm{b}}$ Fish Pathology Lab, CER Groupe, Aye, Belgium \\ ${ }^{\mathrm{c}}$ Aquaculture Research and Education Center (CEFRA), University of Liège, Tihange, Belgium \\ ${ }^{\mathrm{d}}$ Biostatistics and Bioinformatics, Fundamental and Applied Research for Animals \& Health (FARAH), Faculty of Veterinary Medicine, University of Liège, Liège, Belgium \\ ${ }^{\mathrm{e}}$ Biosience Research Institute, Athlone Institute of Technology, Athlone, Co. Westmeath, Ireland
}

\section{A R T I C L E I N F O}

\section{Keywords:}

European eel

Glass eel

Conservation program

Restocking

Sanitary status

Infectious diseases

Parasitic diseases

Anthropogenic spread of pathogens

Quarantine

Biosafety

\begin{abstract}
A B S T R A C T
The anthropogenic spread of pathogens contributes to the decline of some species. However, restocking programs implemented to counteract the decline of such populations can also contribute to the spread of pathogens, in particular for endangered species that cannot be bred in captivity, where populations used in restocking must be sourced from the wild with no control over sanitary status. A prime example of this is the endangered species European eel (Anguilla anguilla). As part of eel restocking programs, glass eels are captured in estuaries for later release further inland. In cases where release occurs immediately after capture, pre-release quarantine is important for mitigation of sanitary risks. In this study, we explored the impact of different quarantine conditions on glass eel sanitary status, morphology, behaviour and quarantine/post-quarantine survival in order to evaluate the feasibility and optimization of quarantine stages. Replicate experiments were conducted in 2017 and 2018 , using glass eels of different geographical origin. The results suggest that glass eels entering estuaries are free of pathogens and so that their capture at this early stage reduces the risk of the anthropogenic introduction of pathogens through restocking programs. They support the use of a 15-day pre-release quarantine period to allow easier management of release processes and the implementation of prophylactic and therapeutic measures as part of these useful conservation programs.
\end{abstract}

\section{Introduction}

Conservation programs of some endangered species involves the artificial restocking of habitats (Black, 1991; Del Mar Gil, Palmer, Grau, \& Balle, 2015; Minterr \& Collins, 2010; Seddon, Armstrong, \& Maloney, 2007). However, due to complex lifecycles, not all endangered species can be bred in captivity. Consequently, some restocking programs must rely on populations captured in the wild (Cabezas, Calvete, \& Moreno, 2006) with unknown sanitary status. Thus, it is possible that such restocking programs may unintentionally contribute to the anthropogenic spread of pathogens (Nettles, Shaddock, Sikes, \& Reyes, 1979).

The restocking of some fish species rely on wild-caught stock, a prime example being the European eel (Anguilla anguilla). This is a semelparous and catadromous fish species that spends most of its lifetime in brackish and freshwaters of Europe and North Africa. Following hatching in the Sargasso Sea, leaf-shape larvae, called leptocephali, gradually metamorphose into a juvenile developmental stage referred to as "glass eels" before entering estuaries to begin upstream migration towards inland freshwaters. At later stages of development, they acquire a yellow colour on their flanks at which stage they are referred "yellow eels". After several years spent in freshwaters they undergo further maturation, and migrate back to the Sargasso Sea to spawn before dying (Berry, Brookes, \& Walker, 1972; Cresci, 2020; Dekker, 2000; Moriarty \& Dekker, 1997; van Ginneken \& Maes, 2005). The numbers of glass eels reaching European

\footnotetext{
* Corresponding author at: Immunology-Vaccinology (B43b), Faculty of Veterinary Medicine, Quartier Vallée 2, Avenue de Cureghem 10, University of Liège, B4000 Liège, Belgium.

E-mail address: A.vdplasschen@uliege.be (A. Vanderplasschen).
} 
coasts are now $1 \%$ of what they were in the early 1980's (Dekker \& Beaulaton, 2016, 2003; Dekker, 2004; van Ginneken \& Maes, 2005), with the International Union for Conservation of Nature (IUCN) now classifying them as "critically endangered" (Jacoby \& Gollock, 2014). This rapid decline has prompted both scientists and authorities to implement measures to counteract this. For example the European Commission's 'Eel Recovery Plan" aims to protect and restore stocks of European eel within member states through several approaches including restocking of inland waters with young eels (Council of the European Communities, 2007). However, it is currently unclear if restocked eels can contribute towards the spawning stock or not. The translocation process may potentially interfere with the natural imprinting of European eel migration routes (Prigge, Marohn, \& Hanel, 2013; Westin, 1998), but some studies on the related Anguilla spp. American eel (Anguilla rostrata) indicate that such environmental factors are not a crucial mechanism in driving normal eel migratory behaviour (Stacey, Pratt, Verreault, \& Fox, 2015). However, there is currently no consensus on whether restocked eels can successfully migrate to spawning grounds (Dekker \& Beaulaton, 2016).

Irrespective of this, there are still important points to consider with regard to the optimal eel developmental stage to use in eel restocking programs. According to individual country policies, the eels used in restocking consist of either yellow eels grown in aquaculture farms (having been initially captured as glass eels), or glass eels released as soon as possible after their capture (with or without pre-release quarantine) (Dekker \& Beaulaton, 2016; ICES, 2019; Josset et al., 2016; Kullmann \& Thiel, 2018; Ovidio, Tarrago-Bes, \& Matondo, 2015; Pedersen, Jepsen, \& Rasmussen, 2017; Simon \& Dörner, 2014; Van Der Hammen, 2018; Wickström \& Sjöberg, 2014). There are three major disadvantages to the use of yellow eels grown in aquaculture farms as restocking subjects: i) artificial feeding is likely to negatively affect the natural feeding behaviour of eels and thus their fitness to survive upon release (Simon \& Dörner, 2014; Simon, Dörner, Scott, Schreckenbach, \& Knösche, 2013), ii) the high population density in captivity has been shown to interfere with sex determination, increasing the proportion of males (Huertas \& Cerdà, 2006; Roncarati, Melotti, Mordenti, \& Gennari, 1997), and iii) the mixing of eel populations from different geographical origins during captivity, together with higher host density resulting in greater contact between individuals (beyond what can naturally occur in the wild), both promote greater transmission and prevalence of pathogens among cultured yellow eel populations prior to release. Thus, restocking with such populations could contribute to the emergence and spread of pathogens in target habitats, as exemplified by the spread of European eel pathogens Anguillicola crassus (Kirk, 2003; Wickström, Clevestam, \& Höglund, 1998) and Anguillid Herpesvirus 1 (AngHV-1) (Kullmann, Adamek, Steinhagen, \& Thiel, 2017).

As an alternative to reared yellow eels, the immediate release of glass eels after capture may help to reduce the three main problems described above. However, this approach is associated with other drawbacks. This includes the fact that the immediate release of glass eels prevents the implementation of informed adaptations to restocking process based on sanitary analyses of each batch of glass eels. It also prevents the potential implementation of prophylactic or therapeutic treatments prior to release. Finally, to minimize the time between capture and release, and thus minimize stress, sometimes eels are released in larger quantities at fewer spots. However, observations suggest that low density and high dispersion release strategies are better to promote long-term survival of glass eels in the wild after restocking (Nzau Matondo, Benitez, Dierckx, Rollin, \& Ovidio, 2020).

In theory, the implementation of a standardized quarantine period after transport of glass eels to the area of restocking could allow the implementation of processes to prevent these drawbacks. Despite the use of quarantine in some countries, the impact of quarantine conditions on the survival rate and the sanitary status of glass eels as well as the potential impact of the quarantine on survival after release in the environment has not been extensively studied (Josset et al., 2016). Thus, the main objective of the present study was to develop experimental quarantine stations for wild-caught glass eels to be used during conservation restocking and compare different quarantine conditions in terms of their impact on eel survival rate, sanitary status, health conditions and ability to support an experimental survival test.

\section{Material and methods}

\subsection{Source of glass eels}

European glass eels (Anguilla anguilla) were obtained during the recruitment phase of two successive years (March 2017 and April 2018) from estuaries of different countries. In 2017, glass eels were obtained from a commercial company located in South of France (Gurruchaga Marée, Henday). In 2018, glass eels originating from the River Severn of the West of England were bought from the UK Glass eel company (U.K. glass eels, Gloucester). Glass eels were transported in styrofoam boxes at a temperature of $10{ }^{\circ} \mathrm{C}$ at the latest 7 days after their capture. The mortality rate at arrival was lower than $0.1 \%$, in both years.

\subsection{Anatomopathological, bacterial, parasitical and viral analyses}

Sanitary and morphologic analyses (SMA) were performed just before and following each survival test experiment (see below and Fig. 2). They were performed by Dr F. Lieffrig at the Belgian reference laboratory for detection of fish diseases. Briefly, five glass eels per condition tank were euthanized using benzocaine (1\%) before necropsy and parasitological examination using binocular and light microscopy. Skin and fins were controlled for external lesions. Fresh smears of skin mucus were examined directly for parasitic or fungal infections using light microscopy (100x to 400x magnifications). Gills were checked using light microscopy for the presence of parasites and lesions. Following dissection, internal organs were examined for lesions and macroscopic parasites. Fresh smears of gall bladder and intestine content were directly examined for the presence of parasites using light microscopy. Notably, the swim bladder was carefully examined for detection of the nematode Anguillicola crassus. After extraction of the visceral mass, the kidney and the parietal peritoneum were examined under binocular microscope. Finally, a fragment of the spleen was squashed gently between a glass slide and a glass coverslip, stained with methylene blue and examined using light microscopy. Virological analyses involved virus isolation assay. The anterior part of 5 glass eels from each tank were pooled (glass eels were transversally cut slightly forward the anus) and grinded using a mortar, a pestle and sterile sand. The grinded tissue were resuspended in $10 \%$ antibiotic culture medium (v) $\mathrm{v}$, penicillin at 5000 units $/ \mathrm{mL}$ and streptomycin at $5000 \mu \mathrm{g} / \mathrm{mL}$ ) and centrifuged at $4000 \mathrm{rpm}$ for $15 \mathrm{~min}$. Serial dilutions of the supernatants obtained were inoculated in duplicates onto three cell lines: (i) Epithelioma papulosum cyprini (EPC) (Fijan et al., 1983), (ii) Blue gill fry (BF2) (Wolf, Gravell, \& Malsberger, 1966) and (iii) Eel Kidney 1 cell lines (EK1) (Chen, Ueno, \& Kou, 1982). EPC and BF-2 were grown in BHK21 medium (Gibco) supplemented with $10 \%$ foetal bovine serum (FBS), 5\% antibiotics (v/v of penicillin and streptomycin), L-glutamine (Gibco Glutamax, ThermoFisher Scientific) and tryptose phosphate broth. EK-1 cell line was grown in Leibovitz L15 medium supplemented with glutamine (Gibco), sodium bicarbonate $10 \%$, 5\% FBS and $0.1 \%$ gentamycine. After inoculation, cells were incubated at $14{ }^{\circ} \mathrm{C}$ in the presence of $5 \% \mathrm{CO}_{2}$. The samples were considered negative for viral isolation when no cytopathic effect (CPE) was observed after 14 days.

\subsection{Biometric analysis}

Glass eels ( $\mathrm{n}=20$ and $\mathrm{n}=10$ per condition, in 2017 and 2018, respectively) were anesthetized with benzocaine $(0.08 \%)$, weighed and measured. In addition, their pigmentation stage was graded using a binocular microscope as described earlier (Elie, Lecomte Finiger, Cantrelle, \& Charlon, 1982). Briefly, stage V corresponds to completely 
transparent glass eel, stage VIA corresponds to the progressive spreading of the pigmentation on both the head and the body, stage VIB corresponds to a widespread dorsal pigmentation while the ventral part becomes opaque, and stage VII corresponds to fully pigmented elvers.

\subsection{Tank for quarantine}

Tanks for quarantine consisted of rectangular glass-made aquaria containing $40 \mathrm{~L}$ of water (length: $60 \mathrm{~cm}$, width: $30 \mathrm{~cm}$, height: $40 \mathrm{~cm}$ ), covered with a glass lid and a protective net to prevent escape (mesh size: $800 \mu \mathrm{m}$ ) (Fig. 1A). Each tank was equipped with an independent recirculating system and a temperature regulator. Floating square feeders were included in the appropriate tanks (Fig. 1B). Shelters made of PVC pipes (length: $15 \mathrm{~cm}$; diameter: $3 \mathrm{~cm}$ ) were placed at the bottom of the tanks allowing hiding and resting behaviours (Fig. 1C). Water salinity was regulated to $5 \mathrm{~g} / \mathrm{L}$. Water parameters were monitored daily; no anomalies were observed.

\subsection{Quarantine experimental design}

Just after their arrival, fish were acclimatized in an $800 \mathrm{~L}$ (water salinity $5 \mathrm{~g} / \mathrm{L}$ ) water tank in which the temperature was gradually increased from $10{ }^{\circ} \mathrm{C}$ to $20^{\circ} \mathrm{C}$ at a rate of $0.5^{\circ} \mathrm{C}$ per hour. No mortality was observed during this acclimatization period. Then, glass eels $(\mathrm{n}=$ 400) were transferred to eight quarantine tanks. A diagram of the experimental design used for the quarantine phases is illustrated in Fig. 2. Briefly, three parameters were tested during quarantine: (i) Water temperature: $20{ }^{\circ} \mathrm{C}$ (T20) or $24{ }^{\circ} \mathrm{C}$ (T24). These temperatures were selected for their positive effect on fish feeding (Ottolenghi, Silvestri, Giordano, Lovatelli, \& New, 2004), their compatibility with fish immunization and their easy implementation in lab condition. (ii) Feeding regime: Feeding (F) or No Feeding (NF). (iii) Duration: 15 days (Q15) or 30 days $(\mathrm{Q} 30)$ of quarantine. The quarantine experimental design consisted of 4 conditions replicated in 2 tanks ( 8 tanks in total). The tank names were designated in accordance with the conditions tested i.e. NF-T20, NF-T24, F-T20 and F-T24. Quarantine conditions without feeding (NF-T20 and NF-T24) were only maintained for the first 15 days post arrival (Q15) for ethical reasons. F-T20 and F-T24 tanks were maintained during the entire study (Q15 and Q30). Consequently, fish were harvested from these tanks at day 15 for SMA and survival test analyses ( $\mathrm{n}=155)$ thereby decreasing the number of fish for the second 15 days of the study $(n=245)$. Hereafter, the name for each condition will be designated according to the time of quarantine, the feeding regime and the water temperature (i.e. Q15-NF-T20 represents glass eels maintained for 15 days of quarantine, non-fed, and at $20^{\circ} \mathrm{C}$, all groups described in Fig. 2). After $48 \mathrm{~h}$ of acclimatization, F groups were fed with cod roe (Commercial Company VariaVis, The Netherlands) at $10 \%$ of their body weight for 7 days (4 times/day). Specially formulated eel starter feed pellets (DAN-EX 2352, BioMar, Denmark) were gradually incorporated to finally replace the cod roe ration (final feeding frequency of 3 times/day) over the course of the second week. Glass eels stocked in $\mathrm{F}$ tanks were all fed simultaneously and noningested feed was removed $3 \mathrm{~h}$ after the feeding. Mortalities were recorded daily in all quarantine conditions and used to generate survival curves.

\subsection{Survival test}

The survival test (ST) was established as follows: glass eels $(n=50)$ were harvested from the original batch at arrival (Q0) or from quarantine tanks (Q15 and Q30) and placed into cages formed by a solid plastic armature surrounded by a hoop net (length: $24 \mathrm{~cm}$; diameter: $12 \mathrm{~cm}$; mesh size: $800 \mu \mathrm{m}$ ) (Fig. 1D). Cages were then transferred to external basins supplied with groundwater (length: $110 \mathrm{~cm}$, width: $110 \mathrm{~cm}$, water height: $33 \mathrm{~cm}$ ) for 15 days. Temperature shift occurred over a period of $1 \mathrm{~h}$. The replicate cages were randomly distributed into three independent open-water basins. At arrival (Q0), 6 groups of glass eels (n $=50$, corresponding to groups described in Fig. 2) were collected from the original batch before the acclimatization period. Following quarantine (Q15 and Q30), 3 groups of glass eels $(n=50)$ were harvested from each duplicate tanks, representing 6 groups of glass eels per condition. Water temperature in the external basins was recorded daily and remained stable all along the experiment (mean temperatures: $14.3^{\circ} \mathrm{C}$ and $14.9{ }^{\circ} \mathrm{C}$, respectively in 2017 and 2018). Fish were not fed during the survival test and the survival rate was calculated by counting the surviving fish at the end of the procedure. Surviving fish were measured and weighted at the end of the survival study.

\subsection{Ethical statement}

The experiments, maintenance and care of fish complied with the
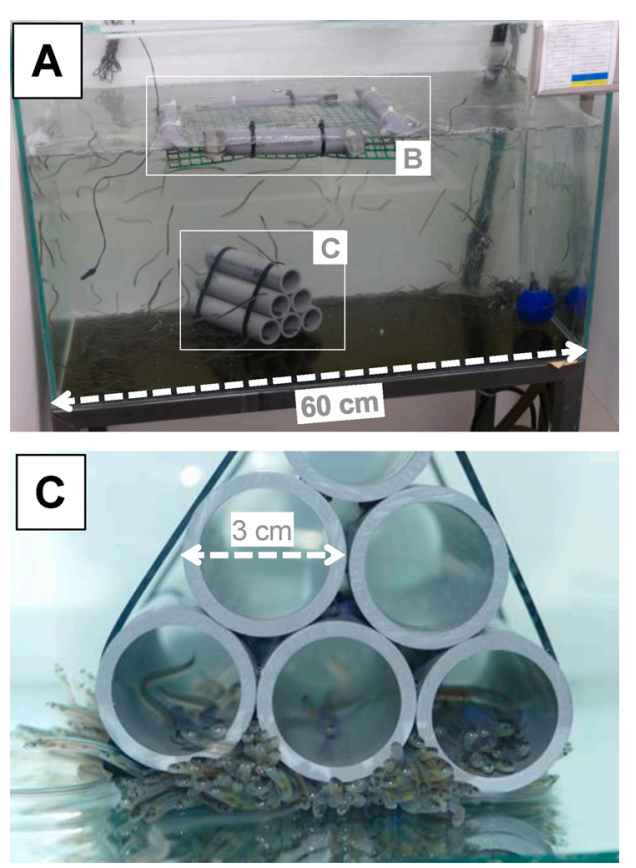

Fig. 1. Illustration of the experimental devices used for quarantine and survival test. (A) Quarantine tank equipped with an individual recirculating biomass filtration system and air supply. The tank contains a floating feeder (B) that allows distribution of cod roe and food pellet as illustrated. A shelter made of PVC pipes is provided at the bottom of the tank (C). (D) Cage used for the survival test. An armature made of PVC pipes ensures stability of the cage and provides shelters for the eels. When running the survival test, the armature is surrounded by a hoop net (mesh size: $800 \mu \mathrm{m}$, left side of the picture). The approximate size of the different

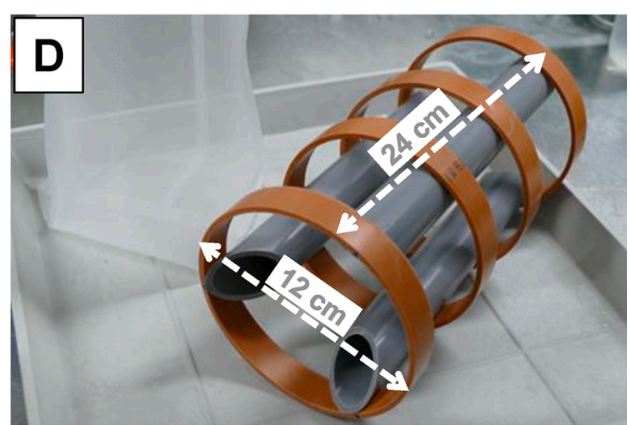




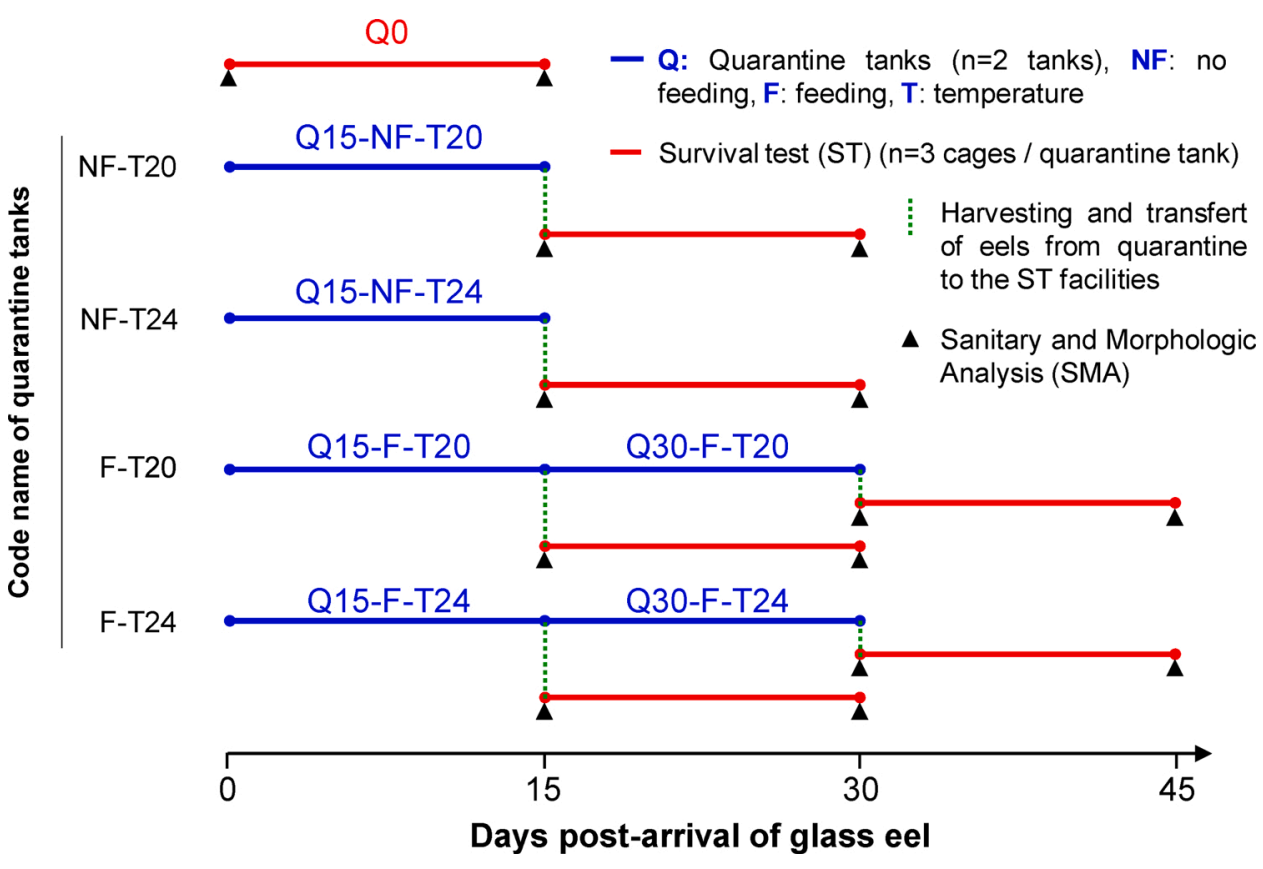

Fig. 2. Flowchart of the quarantine and survival tests.

Following their arrival, glass eels were randomly distributed in 8 quarantine tanks (4 conditions, 2 tanks per condition). The four conditions relied on the variations of two factors, i.e. Feeding (Feeding or No Feeding, $\mathrm{F}$ or NF respectively) and Temperature (Temperature of 20 or $24^{\circ} \mathrm{C}, \mathrm{T} 20$ and T24 respectively). Under the NF conditions, eels were kept for 15 days of quarantine (Q15). Under the $\mathrm{F}$ conditions, eels were kept for 15 or 30 days of quarantine (Q15 and Q30). The different codes (based on the variations of the three main factors Q, F, and T) used for the different quarantine conditions are shown and will be used hereafter. Just after their arrival (Q0) or at the end of each quarantine period (Q15 and Q30), glass eels were harvested and transferred to the survival test (ST) device (dashed green lines). During the ST, eels were housed in the device described in panel D of Fig. 1 for a period of 15 days without feeding. The ST devices were immerged in a flow of water pumped from groundwater and having a mean temperature of $14{ }^{\circ} \mathrm{C}$. ST were preceded and followed by a sanitary and morphologic analysis (SMA, black triangle). Throughout the manuscript, data related to the quarantine period are shown in blue, while data related to the survival test are shown in red. guidelines of the European Convention for the Protection of Vertebrate Animals used for Experimental and other Scientific Purposes (CETS ${ }^{\circ}$ 123). The animal studies were approved by the local ethics committee of the University of Liège, Belgium (laboratory accreditation No. 1610008, protocol no. 1896). All efforts were made to minimize suffering and improve fish welfare.

\subsection{Statistical analyses}

The significance of the impact of the three experimental variables: quarantine time, feeding and temperature ( $Q$, F, and $T$ respectively), on weight, length and survival rates following the quarantine and the survival test, was assessed using a generalized linear model. This was conducted using the glm function in the R Stats package in R (v3.6.2) ( $\mathrm{R}$ Core Team, 2019). To generate p-values for each variable, the model fitted by the glm function was analysed using type III sum of squares test. This was conducted using the Anova function in the "car" package (v3.0-6) (Fox \& Weisberg, 2019) for R, with the default contrast coding in $\mathrm{R}$ adjusted appropriately prior to the use of the glm function to facilitate the use of type III sum of squares tests. In addition, where appropriate, the variances between particular groups and/or that of their corresponding control group (Q0) were compared by Dunn's post hoc test. This was conducted using the Dunn's Test function available as part of the "FSA" package (v0.8.26) (Ogle, Wheeler, \& Dinno, 2019) for R. Survival curves for the quarantine period were generated based on daily mortality records taken during this period. To facilitate an assessment of consistency, for each condition, survival curves for the four replicates ( 2 tank replicates $\mathrm{x} 2$ year replicates) were combined and plotted on single graphs and conditions were compared using the log-rank method using GraphPad Prism (v7.00) (GraphPad software). In order to assess the impact of individual parameters, pairwise comparisons were restricted to conditions that differed by only one parameter $(\mathrm{Q}, \mathrm{F}$ or $\mathrm{T})$. The impact of the survival test on the glass eel morphology (weight/length distribution and correlation) was investigated using GraphPad Prism to conduct linear regression analysis of weight and length data combined for both years (2017 and 2018) and both temperatures (T20 and T24), with the latter not being identified as a significant main effect in all generalized linear models of the morphological data. Where multiple comparisons were made, p-values were adjusted using the Bonferroni method.

\section{Results}

\subsection{Sanitary analysis of glass eels before and after quarantine}

The sanitary analyses were performed on the batch of glass eels collected in 2017 and 2018. The necropsy of euthanized glass eels, just after their arrival, confirmed the absence of external and internal lesions. Similarly, parasitological, bacterial and virological analyses were all negative. Importantly, sanitary analyses after quarantine and survival tests yielded the same results indicating no deterioration of the health between the initial and final testing periods.

\subsection{Morphology and behaviour of glass eel following quarantine}

Following arrival, glass eels were submitted to the quarantine procedures (Fig. 2). The procedures included a survey of glass eel body condition (weight and length), pigmentation stage and behaviour. Body condition data obtained during 2017 and 2018 at arrival (Q0 group only, see Fig. 2) and following the quarantine procedures (for all other groups, as per Fig. 2) are presented in Fig. 3. In order to determine if the three experimental variables - quarantine time, feeding regime and temperature $(\mathrm{Q}, \mathrm{F}$, and $\mathrm{T}$ respectively), significantly affected weight during quarantine, data corresponding to measurements of weight taken after quarantine was analysed using generalized linear models. The results obtained showed that feeding regime (F) and quarantine (Q) had a significant impact on weight in the 2017 replicate, but not in the 2018 replicate. Temperature (T) had no significant impact on weight in either year. However, identification of F and Q as main effects in 2017 was caused by lower weights within the NF groups. Specifically, there were significant differences between Q15-F and Q15-NF groups in 2017, however, there was no difference between the Q15-F and Q30-F groups 

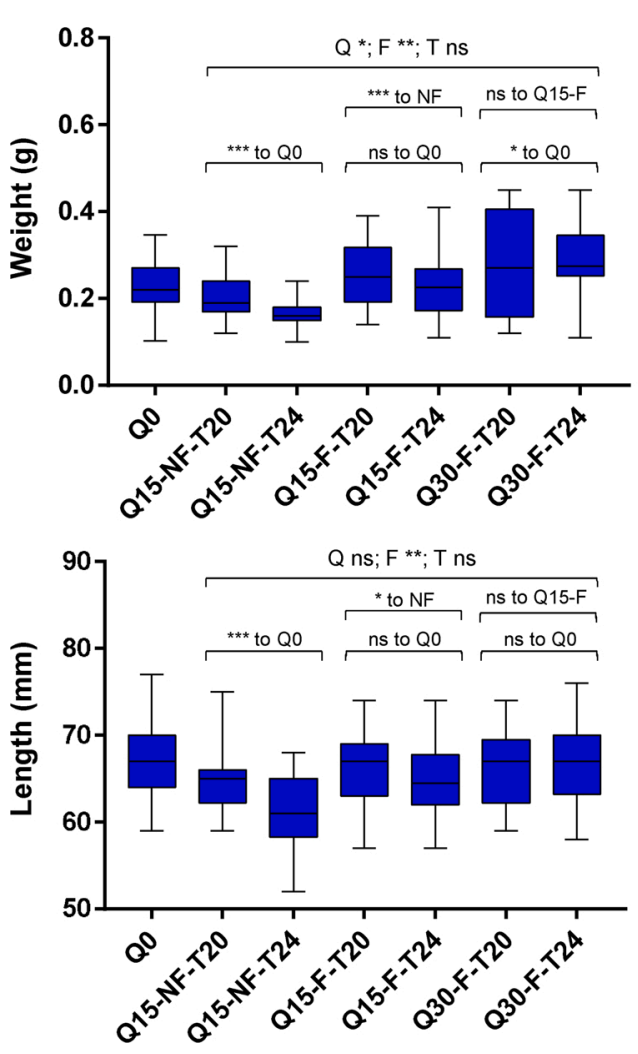

2018
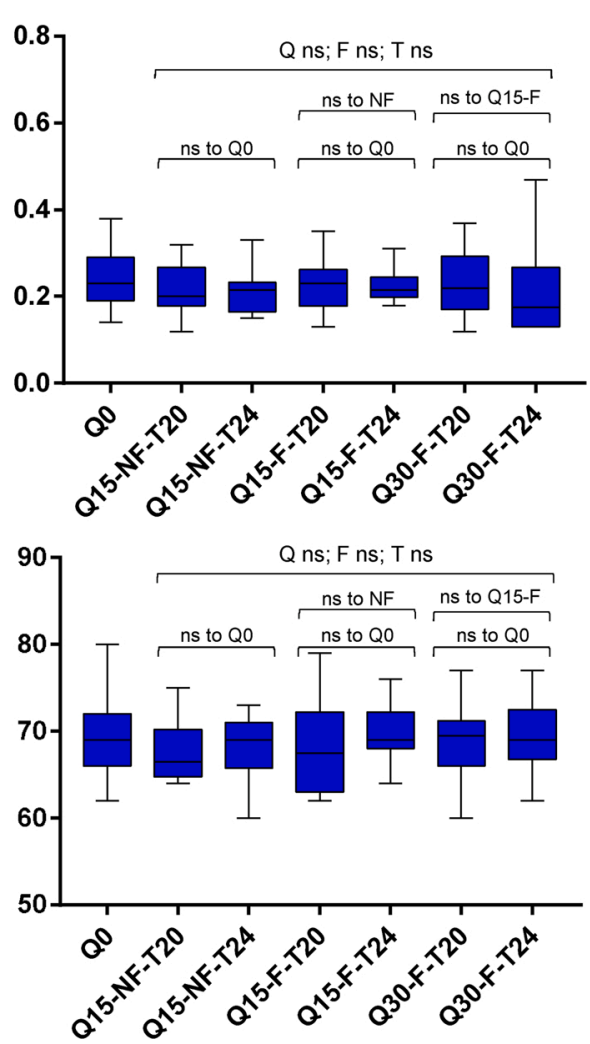

Fig. 3. Morphologic analysis following quarantine.

Glass eels (2017, left panels $\mathrm{n}=20$; 2018, right panels $n=10$ per condition) were weighed and measured at arrival (Q0) and following the quarantine periods (Q15 or Q30). Data are presented as box and whiskers plots (Box: median, 25th-75th percentiles; Whiskers: Min and Max). In order to determine if the three experimental variables (quarantine time, feeding regime and temperature; $\mathrm{Q}, \mathrm{F}$, and $\mathrm{T}$ respectively) significantly affect weight and length, the data were analysed using generalized linear models. The findings from the generalized linear models are shown in the top tier statistical comparisons above each plot. In addition to this, the results of multiple comparisons tests between groups, (middle tier above each plot), and comparisons to control data (Q0) are presented in the middle and lower tiers above each plot. in either year. Additional comparisons revealed that in both years, weights were lower in the Q15-NF groups and higher in the Q30-F groups relative to measurements taken upon arrival (Q0), but these differences were only significant in 2017. Similar results were obtained for fish length (Fig. 3).

The pigmentation stages of glass eels at arrival were heterogeneous and mainly represented by stages VB (24\%), VIA0 (36 \%) and VIA1 (26 $\%)$. The pigmentation stages did not evolve significantly during quarantine, with the only observation made being the appearance of some VIA3 stages at the end of the quarantine period. Evolution of the pigmentation stages were roughly independent of the conditions used during the quarantine phase (data not shown).

Unlike the survival tests (where it was not practical to do so), the quarantine phase presented an ideal opportunity to monitor behaviour. The vast majority of the fish showed good adaptation to quarantine conditions. Following the food distribution (F groups), fish responded well and started ingesting the cod roe rations. However, a small subpopulation of fish (around 5\%) did not start to feed and either maintained a stable body condition or displayed a slight decrease during the quarantine phase. In parallel to food intakes, fish activity increased in the F groups, specifically, it was observed that eels had a notable tendency to exhibit a preference for remaining in close proximity to incoming filtered water (i.e. upstream water) flows, reflecting a natural instinct to swim against the current. Fish in the NF groups did not express evident signs of distress but remained more inactive, spending most of the time hidden in the shelters at the bottom of the tanks. Also, a low amount of cannibalistic behaviour was observed in the Q30-F-T20 and Q30-F-T24 groups.

\subsection{Viability of glass eels during quarantine}

Results of the viability observed during the quarantine conditions are shown in Fig. 4. Individual survival curves of fish with respect to the duration of quarantine are shown in Fig. 4A, while mean survival rates per condition are shown in Fig. 4B. In general, the viability during quarantine was high in all the experiments performed both in 2017 and 2018 (mean survival $>95 \%$ in all conditions tested). Comparison of the survival data indicated that duration of quarantine time $(Q)$ was the factor that had the greatest impact on survival. Firstly, most mortalities were observed during the first 15 days of quarantine (Q15 groups), while mortalities were very limited during the second 15 days (Q30 groups) (Fig. 4A). Secondly, the most significant and consistent differences in survival curves were between the Q15-F and Q30-F groups (Fig. 4A). Thirdly, Q had a significant impact on survival but only in 2017 (Fig. 4B). Further analysis revealed that this was due to significant differences between Q30-F and Q15-F groups in that year (Fig. 4B). The results also indicated that $\mathrm{T}$ and $\mathrm{F}$ have a relatively low impact on the overall survival curves and rates following the quarantine phase. Surprisingly, F was not identified as having significant impact on the survival rate, despite observed differences in body weight and behaviour during this period. As mortalities were either null or rare during the second 15 days of quarantine (Q30 groups), it indicates that there was good medium-term adaptation to the quarantine stations and/or the negative selection of weak subjects during the first 15 days (Q15 groups).

\subsection{Morphology of glass eels following the survival test}

As per after the quarantine periods (Fig. 3), morphological analysis of eels was also conducted after the survival test in order to determine if the experimental parameters impacted the final body condition (Fig. 5). In contrast to the results of morphological analysis obtained following the quarantine phase (where feeding regime was observed as significant in Fig. 3), the main parameter affecting the body condition after the survival test was the amount of time eels were kept in quarantine (Q), with longer times having a positive effect on both weight and length 
A

$$
\text { Q15 - NF - T20 } Q \text { Q15 - NF - T24 }
$$

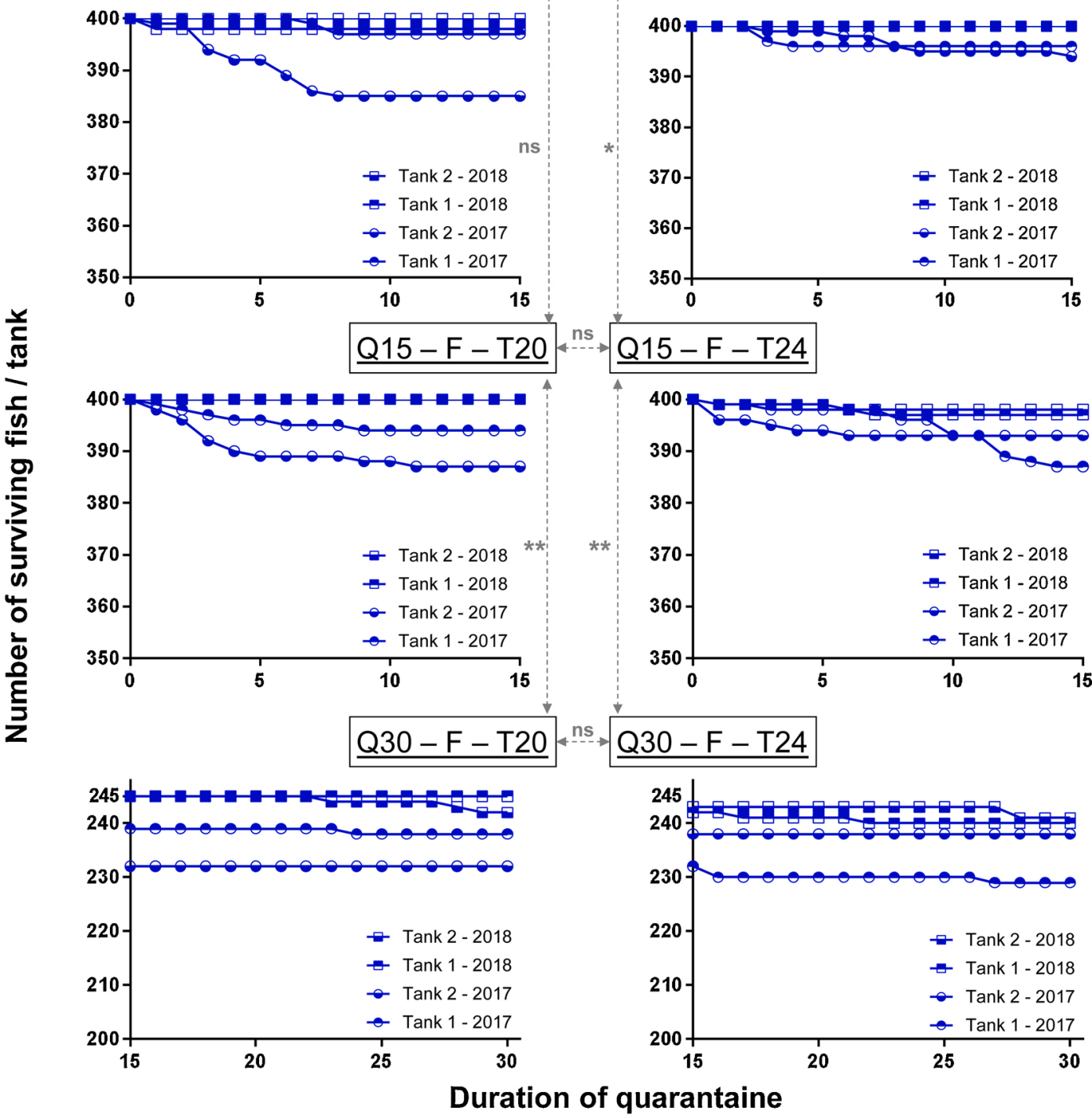

B
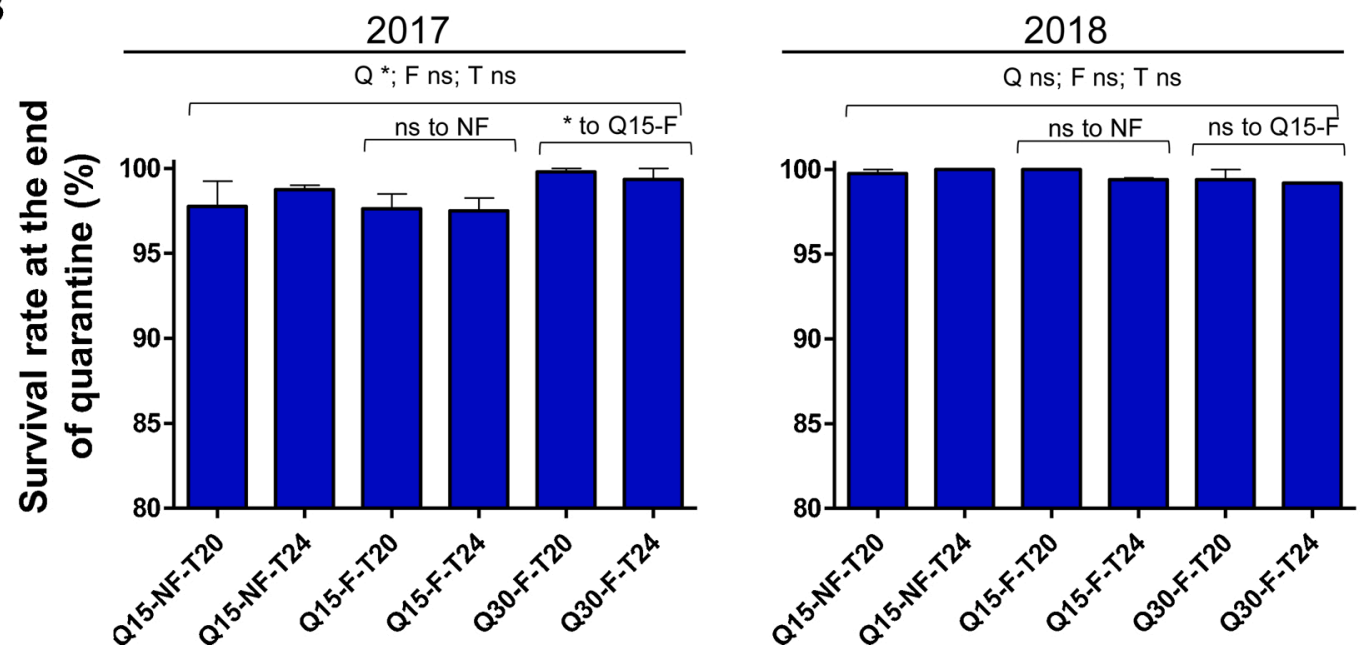

(caption on next page) 
Fig. 4. Viability of glass eels during the quarantine period.

(A) Survival curves of glass eels during the quarantine period. Glass eels were distributed randomly into 8 tanks ( 4 conditions, $n=2$ tanks per condition, $\mathrm{n}=400$ glass eels per tank). Mortalities were recorded daily. Data are represented as the absolute number of surviving fish with respect to duration of quarantine. Note that given the experiment design in Fig. 2, the Q15-F-T20 and Q15-F-T24 data also represents the survival rate for the first 15 days of the Q30-F-T20 and Q30-F-T24 groups (i.e. sharing F-T20 and F-T24 tanks). Consequently, as 155 fish were removed from the tanks after the first 15 days of quarantine to perform the SMA and post-quarantine period survival test (for Q15-F-T20 and Q15-F-T24 groups), the remaining fish (maximal $n=245$ minus the number of mortalities during quarantine) were used to study survival in the second 15 days (Q30-F-T20 and Q30-F-T24). For each individual condition (6 conditions in total), the four replicates (2 tanks $\mathrm{x} 2$ years) were combined and compared to each other using the log-rank method. To look at the effect of varying individual parameters, pairwise comparisons was restricted to conditions that differ by only one parameter (Q, F or T) and p-values were adjusted for multiple analysis. (B) Survival rates at the end of quarantine. Data are represented as the mean final survival rate \pm SD obtained from the two independent duplicate tanks used per condition. Note that for the Q30-F-T20 and Q30-F-T24 conditions, final survival rates were calculated taking the number of surviving fish at day 15 as a reference. In order to determine if the three experimental variables (quarantine time, feeding regime and temperature; Q, F, and T respectively) significantly affect survival, the data were analysed using generalized linear models. The findings from the generalized linear models and subsequent multiple comparisons between groups are presented on the top and lower tier respectively.
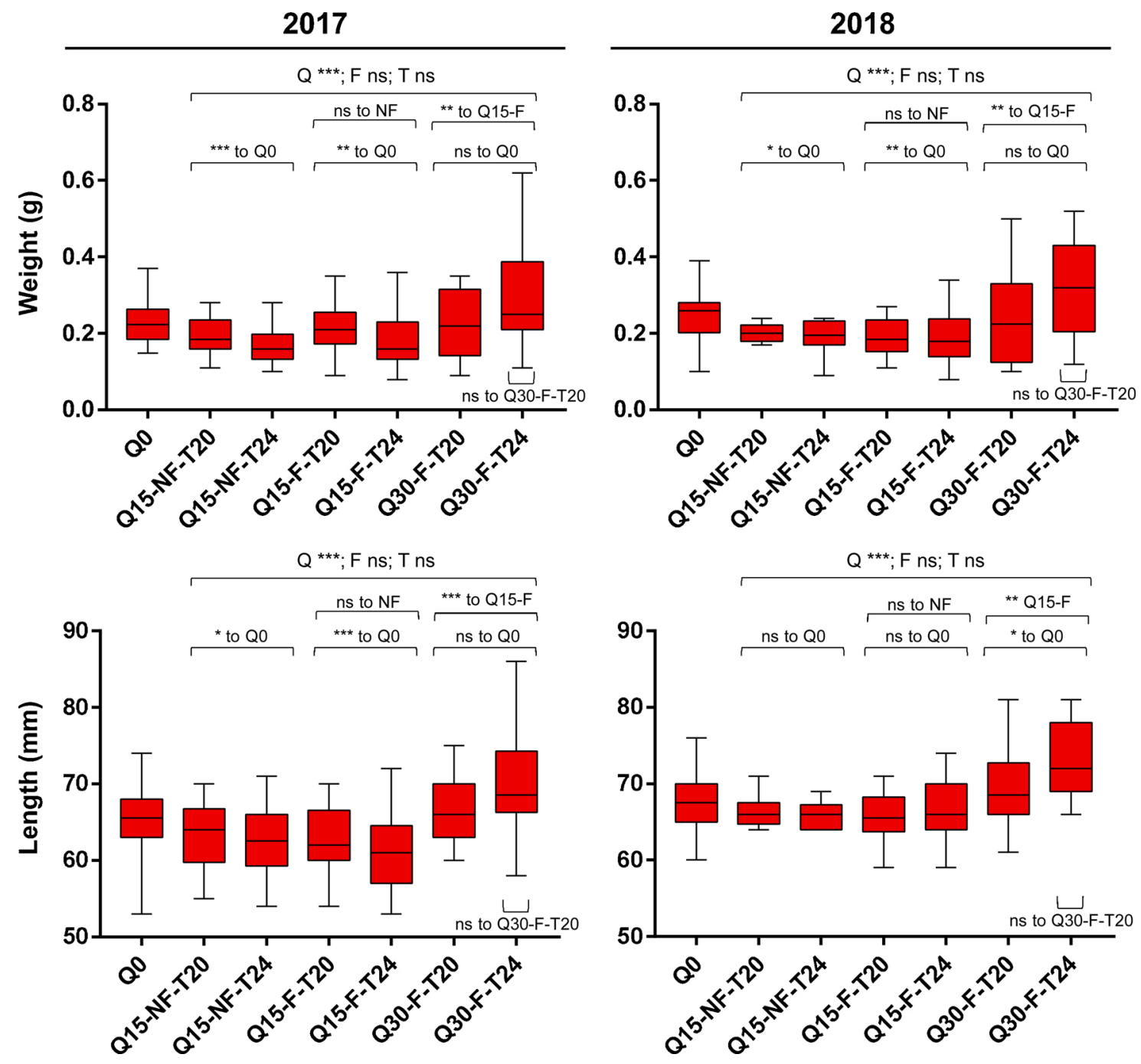

Fig. 5. Morphologic analysis following the survival test (ST).

As with morphological analysis after the quarantine period in Fig. 3, glass eels (2017, left panels $n=20$; 2018, right panels $n=10$ per condition) were weighed and measured at arrival (Q0) and following the survival test (Q15 or Q30). Data are presented as box and whiskers plots (Box: median, 25th-75th percentiles; Whiskers: Min and Max). In order to determine if the three experimental variables - quarantine time, feeding regime and temperature (Q, F, and T respectively), significantly affect weight and length, the data were analysed using generalized linear models. The findings from the generalized linear models are shown in the top tier statistical comparisons above each plot, with the significance of each parameter shown above the tier. The findings from the generalized linear models, multiple comparisons between groups, and comparisons to control are shown in the top, middle and bottom tiers respectively above each plot.

(Fig. 5). This significant effect was observed in both 2017 and 2018 for both the weight and length data. Specifically, in both years, the weights observed in both Q15-NF and Q15-F datasets, were significantly lower than Q0 with no significant difference between Q30 and Q0 datasets. Similar results were obtained for length datasets in 2017, but in 2018, the Q15-NF and Q15-F showed no significant difference in length to Q0, and furthermore, Q30 was significantly greater than Q0 that same year (Fig. 5). Interestingly, although temperature was not found to have a significant impact on weight and length as a "main effect" in the generalized linear model, it did identify a significant interaction 
between temperature and quarantine time both in the weight and length datasets ( $p>0.05 *$ and $p>0.005 * *$ respectively) for the 2017 samples. Indeed, as evident from the plots in Fig. 5, a relationship can be observed between temperature and quarantine time in Q30 groups in both years, with higher weights and lengths consistently observed in the 30-F-T24 relative to 30-F-T20 groups in both years. However, no significant difference was found between these groups in either year.

Notably, it was observed that for some groups, the ranges in weight and length measurements were slightly larger after the survival test (Fig. 5) compared to the ranges observed after quarantine (Fig. 3). In order to investigate this increased heterogeneity further, the relationship between weight and length was examined within each group before (i.e. after quarantine) and after the survival test and then compared. This comparison revealed that there was no significant change in the relationship between weight and length after the survival test (Fig. 6).

\subsection{Viability of glass eels following the survival test}

Survival tests were performed at the time of glass eel arrival and after each quarantine period (Fig. 2) to estimate the fitness of subjects in terms of resistance to stress and to compare the impact of quarantine conditions to their estimated chance of survival at the time of release into the wild. The final survival rates of glass eels obtained following the survival test are presented in Fig. 7. In general, glass eels remained healthy and did not show any signs of suffering or lethargy during the survival test. This observation was supported by the relatively high survival rates obtained following the survival test throughout the study irrespective of the associated quarantine conditions, even in absence of quarantine or recovery period for the Q0 group (mean survival rates $>90 \%$ for all conditions tested in both 2017 and 2018). The duration of quarantine was the only parameter found to have a significant impact on survival. However, in contrast to the analysis of survival during quarantine (i.e. before the survival test study, Fig. 4), a quarantine time of 30 days (Q30) had a significant negative impact on the viability of glass eels

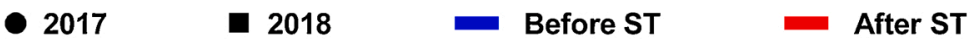

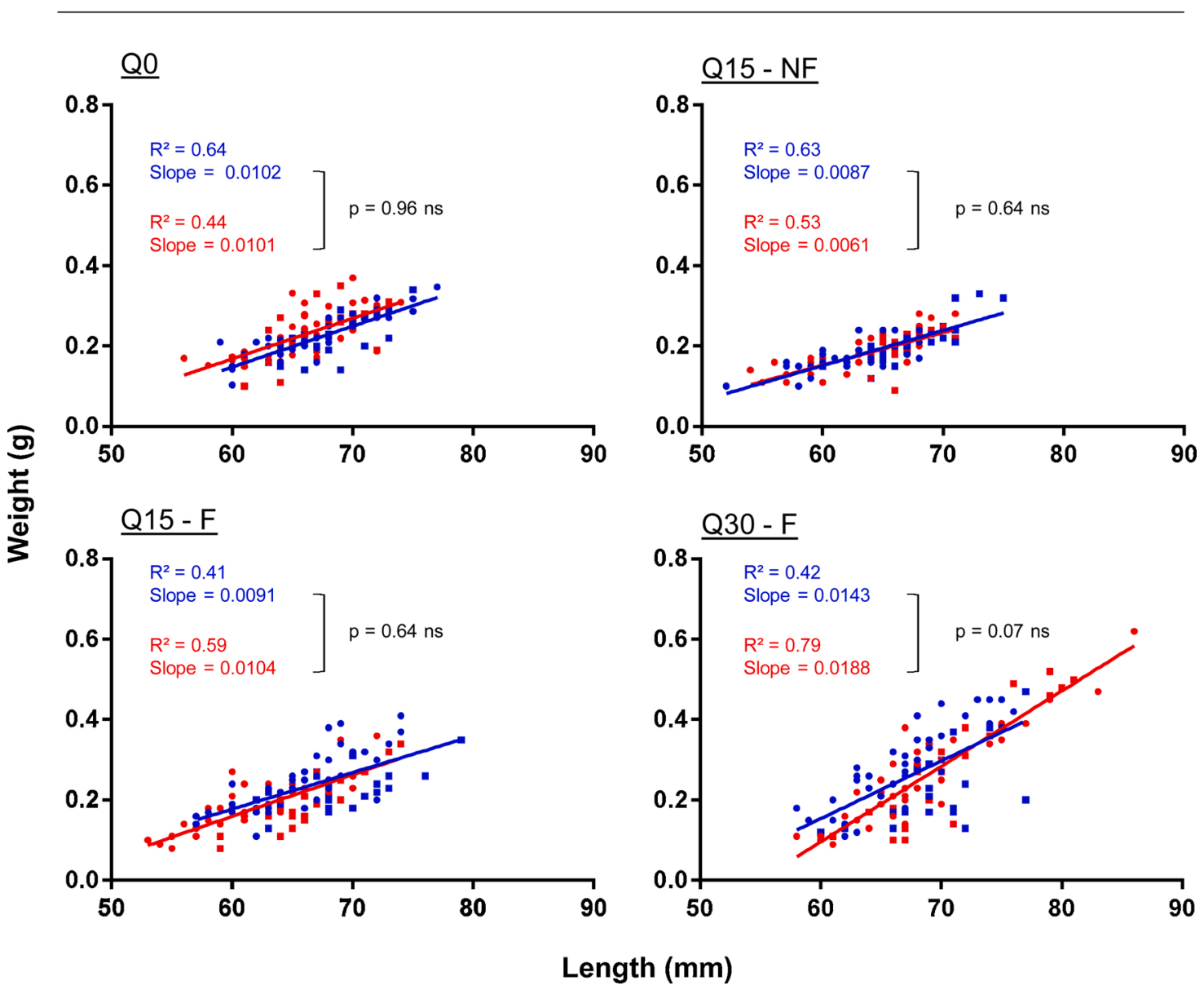

Fig. 6. Impact of the survival test on glass eel morphology.

The impact of the survival test on the glass eel morphology (weight/length distribution and correlation) was investigated using linear regression analysis of weight and length data. Morphological data from Q0, Q15-NF, Q15-F and Q30-F groups were plotted with length on the X axis and weight on the Y axis with data from both years (2017, $n=20 ; 2018, n=10$ per condition) and both temperatures (T20 and T24) combined within each group - the latter not being identified as having a significant influence (as a main effect) on weight and length in any generalized linear models of the morphological data examined in this study. For each condition, data from periods before (i.e. after quarantine) and after the survival test, were plotted in each graph and indicated in blue and in red respectively. Within each graph, each plot was compared using linear regression analysis, with both slopes and $\mathrm{R}^{2}$ values for data obtained before (i.e. after quarantine) and after the survival tests are shown. The statistical significance of the difference between the before and after plots within each graph (representing each group of conditions), are also shown. This revealed that the survival test did not significantly affect the weight/length distribution or correlation in the Q0, Q15-NF and Q15-F groups, with the slopes being similar. The slopes obtained in the Q30-F condition before and after the survival test were less similar, but the significance of this difference ( $p=0.07$ ) was slightly above the critical p-value of 0.05 and thus not accepted as significant. There was no statistically significant difference observed between data recorded before and after the survival test. 
2017

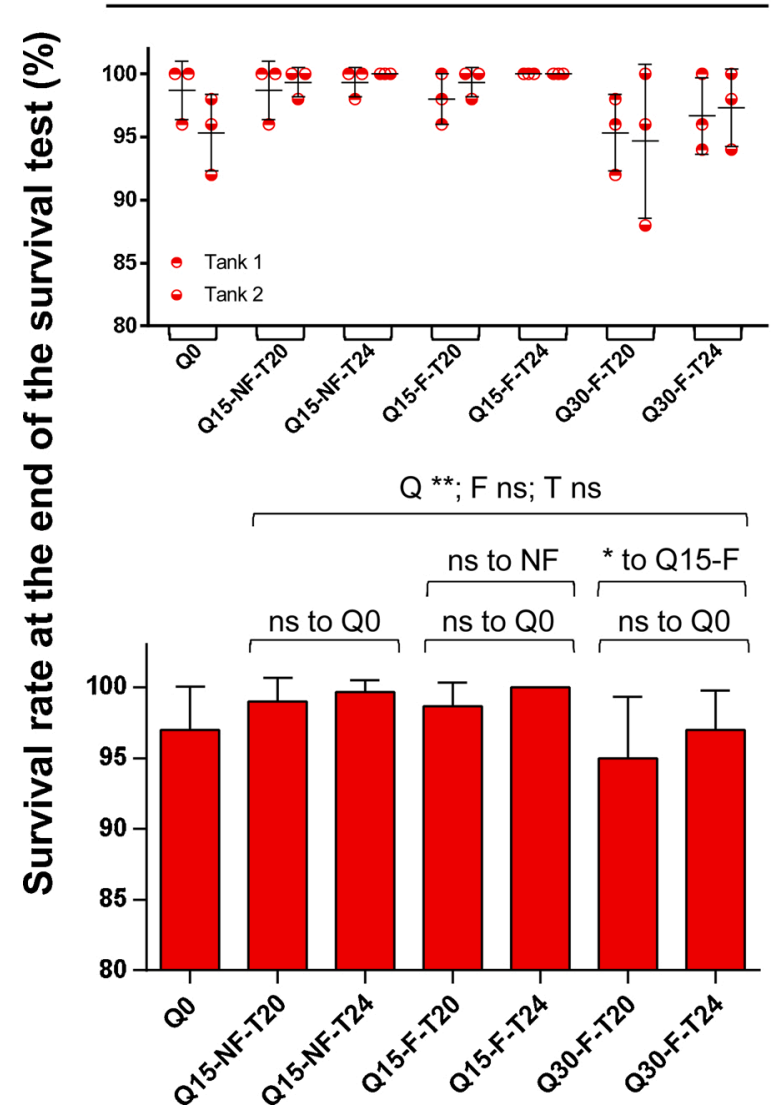

2018
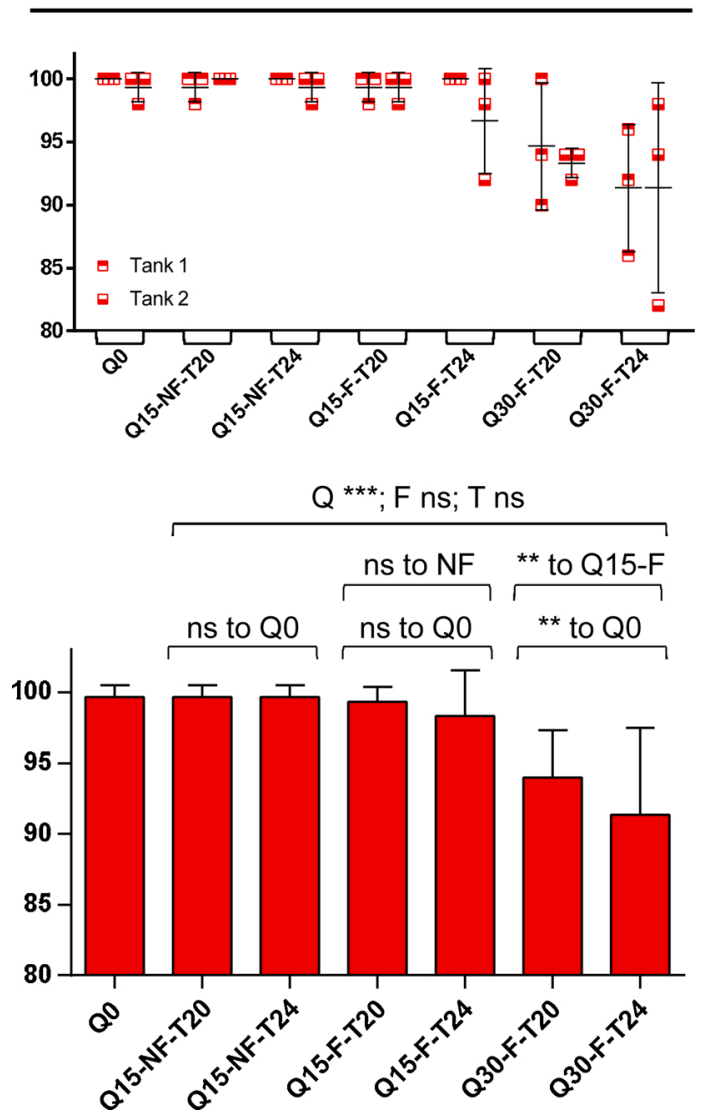

Fig. 7. Survival rate of glass eels at the end of the survival test.

Just after their arrival (Q0) or following a quarantine period (Q15 and Q30), glass eels were harvested and transferred into the survival test device (Panel D, Fig. 1). The survival studies were performed in similar conditions (regardless of the previous quarantine procedure), i.e. no feeding, stable temperature $\left(\sim 14{ }^{\circ} \mathrm{C}\right)$ and for a period of 15 days. Glass eels were distributed in cages submerged in three independent external tanks supplied by ground water $(\mathrm{n}=3$ cages per quarantine tank, $\mathrm{n}=$ 50 glass eels per cage). After a period of 15 days, the number of surviving fish were recorded and survival rates calculated. The two upper panels illustrate raw data and mean survival rate \pm SD obtained per quarantine tank and per condition ( $\mathrm{n}=3$ tanks per condition). The two lower panels represent the mean survival rate \pm SD per condition ( $\mathrm{n}=6$ tanks in total). Statistical analysis were done using generalized linear models using quarantine time, feeding and temperature as experimental variables (Q, F, and $\mathrm{T}$ respectively). The findings from the generalized linear models, multiple comparisons between groups, and comparisons to control are shown in the top, middle and bottom tiers respectively above each plot.

during the survival tests both in 2017 and 2018 (Fig. 7). Specifically, there was a significant reduction in the survival rates within the Q30 groups relative to the Q15 groups in both 2017 and 2018 (Fig. 7). This is the opposite to the effect that quarantine had on the weight and length of glass eels following the survival test (Fig. 5), where there was a positive correlation associated with the longer quarantine period. Furthermore, in both years, the survival rate in the Q30 groups were lower than in their respective Q0 control groups, but this difference was only significant in 2018. Conversely, a short duration quarantine time (with or without feeding) did not affect the survival rate at the end of the survival test compared to the Q0 control, in both years there was no significant difference between the Q15-F and Q15-NF groups and the Q0 controls (Fig. 7). Finally, as evident in the top panel of Fig. 7, there was more heterogeneity in survival rates data for the Q30 group compared to the Q0 and Q15 datasets. This heterogeneity in survival rates correlates with the patterns of heterogeneity observed for weights and lengths of glass eels following the same survival tests (Figs. 5 and 6), in both cases being most pronounced in the Q30 group.

\section{Discussion}

The anthropogenic involvement in the decline of global biodiversity has culminated in what has been sometimes referred to as the "Holocene
Extinction" or "Sixth Mass Extinction" among other terms (2015, Braje \& Erlandson, 2013; Ceballos, Ehrlich, \& Dirzo, 2017; Sandom, Faurby, Sandel, \& Svenning, 2014; Scheele et al., 2019). A major element of this is the breakdown of natural barriers to pathogen dispersion with human movement of animals (Gaughan, 2001; Kock, Woodford, \& Rossiter, 2010). The implementation of restocking programs may sometimes have also led to the unintentional spread of pathogens (Chipman, Slate, Rupprecht, \& Mendoza, 2008). In particular, this may be a problem when the target endangered species cannot be bred in captivity. Such programs rely on populations captured in the wild with less control with regard to the initial sanitary status of such populations. The artificial movement of live fish is also a major cause of pathogen introduction and spread between regions. European eel restocking programs represent a good example of this. The rapid global dissemination of the eel pathogen Anguillicola crassus was not only due to the natural migration of eels, but also facilitated by the global practice of transporting eels for aquaculture and restocking of wild ecosystems (Kirk, 2003; Wickström et al., 1998). Another prime example is the introduction of AngHV-1 to a fjord in Germany, previously free of this virus (Jakob, Neuhaus, Steinhagen, Luckhardt, \& Hanel, 2009) through the movement of infected eels from an aquaculture facility as part of a restocking process (Kullmann et al., 2017).

The use of glass eels in European eel restocking programs as an 
alternative to yellow eels raised in aquaculture systems has a lower risk of anthropogenic spreading of pathogens, especially if a pre-release quarantine period is implemented. The use of standardized quarantine period for glass eels prior to release, as implemented in some regions, has many advantages. The potential benefits of implementing a shortterm quarantine period are (i) establishment of a recovery period for eels following the stress induced by the capture, handling and transport; (ii) increased time to facilitate more thorough organization of logistical matters and decision making processes associated with the modification and optimization of release actions and strategies; (iii) time to engage in the implementation of standard operating procedures to monitor health and epidemiological status of eels to be released and to integrate the results of these analyses in the modification and rational epidemiological management of restocking processes; and (iv) time to engage in the implementation of therapeutic and/or prophylactic treatments (assessment of sanitary status, vaccination) to optimize the effectiveness and reduce the risks associated with restocking programs.

However, for the optimisation of pre-release quarantine periods, it is important that we understand the impact that different quarantine conditions can have on the sanitary status and survival rate of glass eels. To examine the impact of different quarantine conditions and to identify optimum parameters, a comparative study was performed in which three parameters were varied (temperature, feeding and quarantine duration). Correlations observed between survival rate, sanitary status, general health conditions during quarantine and the outcomes of experimental survival studies after quarantine, indicated that a 15-day quarantine period without feeding is suitable, without any major negative effects on the animals.

Overall, the steady state survival rate observed during the quarantine phase was high throughout the study (90-95\% depending on the phase), independent of the conditions tested. The few reported mortalities were mainly observed during the first week after arrival most probably reflecting the negative selection of weaker animals that did not adequately adapt to the freshwater environment. A similar conclusion was reached in an earlier study (Josset et al., 2016). During the quarantine phase, glass eels remained fully healthy; no significant lesions associated with the quarantine facilities or processes were observed. In addition, no infectious agents were detected during the quarantine phase or after the survival test. All these positive favorable indicators observed were reflected in the fact that the survival test performed following quarantine showed extremely high survival rates comparable to non-quarantined (Q0) glass eels. However, the data obtained in 2018, but not in 2017, suggested that a quarantine period of 30 days results in a small yet significant reduction in survival relative to quarantine periods of 15 days. We observed the opposite effect in terms of morphology, where a longer quarantine period of 30 days resulted in a statistically significant increase in both weight and length relative to groups going through a 15-day quarantine period. However, this may be explained by the fact that during the quarantine period low amounts of cannibalistic behaviour was observed in this group specifically, leading to a possible increase in this cannibalistic behaviour during the survival test once regular feeding was stopped. Indeed, this may be more likely to affect the Q30 groups than any other, as the longer feeding periods during quarantine result in more extreme disparities in size within these groups (Fig. 3), with larger eels more likely to prey on smaller ones during quarantine. Once feeding was discontinued during the survival test, cannibalistic behaviour (with some eels already primed to engage in this behaviour from the quarantine period), may have increased within the Q30 groups, and thus may have led to the increased disparities in size (Fig. 5), and of course, reduced survival rates for this group (Fig. 7) following the survival test. However, it is important to note that this cabalistic behaviour may have been facilitated by the nature of the survival test itself. For instance, unlike the experimental conditions, upon release into the wild after quarantine, eels would no longer be in close confinement and not necessarily without sources of food, thus reducing the potential for cannibalistic behaviour. Therefore, for these reasons, it is possible that the experimental conditions may have artificially decreased survival rates observed in the Q30 group post survival test. In contrast to the Q30 groups, the survival tests revealed that the fed and non-fed groups that went through a 15-day quarantine period exhibited no significant difference relative to the Q0 control groups. This suggests that a 15-day quarantine may have no significant negative effect on glass eel fitness or survival potential after release into the wild, and thus, these may represent more suitable quarantine conditions. Furthermore, the nonfeeding condition may in fact represent the optimum option for two key reasons. Firstly, by definition, this option involves less hands-on time and cost. Secondly, it has been suggested that farmed eels used in restocking may exhibit a reduced ability to feed naturally in the wild (Pedersen \& Rasmussen, 2015; Simon et al., 2013), thus the absence of feeding during quarantine periods may help conservation programs to avoid the possible drawbacks of artificial feeding, helping to increase the viability of released eels.

The survival test used in this study was designed in a way that would allow comparable conditions to be maintained and sustained over time between different experimental groups, allowing direct comparison of survival data generated from each group. Indeed, the tanks, water supply and the temperature remained stable over the entire course of this experiment. However, it is clear that this survival test does not mimic all the stresses and selection pressures corresponding to a direct release into the wild. Therefore, in the case of the Q15 groups, the experimental conditions possibly led to an overestimation of survival rate compared to the wild, but in order to facilitate valid comparisons, these conditions were deliberately chosen to minimize environmental variability between experimental groups.

The very low mortalities observed following the survival test in the non-quarantined groups (Q0) suggested no potential benefit in using quarantine facilities to maximise fish survival in the wild. However, this conclusion should be taken with caution. First, it has to be noted that the survival rates obtained in our study are probably maximised by the very limited handling performed for the Q0 groups in our research facilities, and by the likely overestimation of the survival in these groups due to the nature of the survival tests used (see earlier). The situation might be more complex in the field. Furthermore, given the limitations of the survival test implemented in this study, our own critical assessment of this reinforces the importance and potential value in combining this type of experimental design with the monitoring of short, medium and longterm eel survival after transfer to mesocosms or even reintroduction in the wild following exposure to various quarantine conditions. Indeed, as also suggested by others (Josset et al., 2016), the integration of factors such as field conditions is important in this context, and it is something that may need to be considered in any future experiments.

In the present study, glass eel populations from two different geographic origins, in the two consecutive years, all exhibited excellent sanitary status. These results suggest that glass eels entering fresh water are free of pathogens and get contaminated later when they migrate upstream in inland waters. Even if further studies are required to confirm this conclusion, the present study supports the use of glass eels that are caught as early as possible in estuaries when they have had minimum contact with older eels or pathogen vector species before restocking. However, threatening pathogens such as Gyrodactylus anguillae or EVEX (rhabdovirus) have been isolated in wild glass eels used for restocking (Grano-Maldonado et al., 2011; ICES, 2018; Peeler, Gardiner, \& Thrush, 2004) demonstrating that indeed, batches of glass eels can become infected with pathogens and therefore can represent a potential biosafety risk when used in restocking programs. Therefore, a major positive aspect of using quarantine stations for glass eels is the possibility to implement systematic sanitary analyses of restocking batches and to exploit this information in the epidemiological management of restocking programs. Furthermore, this approach may be combined with prior epidemiological surveys of areas to be populated in order to ensure that restocking processes do not contribute to the introduction of new pathogens to these ecosystems. Interestingly, 
diagnosis of infectious diseases could also be coupled with appropriate and specific therapeutic or prophylactic measures before restocking. Interestingly, glass eels have been shown to be immunocompetent at this early developmental stage (Nielsen \& Esteve-Gassent, 2006), therefore, it is plausible that during pre-release quarantine periods, SPF glass eels could be vaccinated against pathogens endemic to release regions, promoting increased survival upon release, and thus increased efficacy of restocking programs. Such approaches, where pre-release quarantine periods have been used to protect released individuals against endemic pathogens has been applied with success elsewhere, for example, vaccination against rabbit haemorrhagic disease in restocking programs using wild-caught rabbits (Cabezas et al., 2006). Also, in doing so, this would ensure that implementation of restocking programs is not limited to disease-free regions. Therefore, additional studies into the characterization of the glass eel immune system together with the development of vaccine candidates should be encouraged given the potential benefits in both commercial and conservation contexts (Esteve-Gassent, Fouz, Barrera, \& Amaro, 2004; Fouz et al., 2001).

\section{Conclusion}

Restocking programs are important conservation tools. Although there is no current consensus on the effectiveness of European eel restocking programs, undoubtedly, the continued optimization and reduction of associated risks will play an important role in the future of such endeavors. On this note, here, we conclude that the introduction of a short-term pre-release quarantine in glass eel restocking programs is feasible, and can be implemented without any major negative effect on the animals. Specifically, we have found that limiting the duration of the quarantine to 15 days (or two weeks) without feeding is suitable under the experimental conditions used. Indeed, this information may be exploited in the planning and implementation of future European eel restocking programs, and in the introduction of further measures to optimize the efficacy, biosafety and overall success of such programs. In addition to obvious benefits related to easier management of the restocking programs, given timeframes typically required for completion of standard molecular diagnostic, viral or bacterial culture based tests, the implementation of a 15-day quarantine stage may be more than sufficient to facilitate the matching of the sanitary status of glass eels to be released with the epidemiologic record of the habitat to be repopulated. Importantly, it would facilitate the implementation of prophylactic and therapeutic treatments prior to release, allowing a more holistic approach to European eel conservation.

\section{Declaration of Competing Interest}

The authors report no declarations of interest.

\section{Acknowledgments}

Natacha Delrez is a research fellow of the Belgian Fund for Scientific Research - FNRS (Belgium). Haiyan Zhang is a research fellow of the Chinese Scholarship Council. Owen Donohoe is a Marie Curie research fellow of the European Union. This work was supported by the University of Liège (ARC15/19-12), the FNRS (CDR J.0094.15 and PDR T.0241.19), the Walloon Region and the European Maritime and Fisheries Fund (EMFF, Eel4ever project). The authors are grateful to Emeline Deglaire, Gwladys Meesemaecker, Aurélie Vanderlinden, Justine Javaux and Lorène Dams for excellent technical assistance. The authors declare no conflict of interest.

\section{References}

Berry, L., Brookes, D., \& Walker, B. (1972). The problem of the migration of the European eel (Anguilla anguilla). Science Progress (1933-), 60, 465-485.
Black, J. M. (1991). Reintroduction and restocking: Guidelines for bird recovery programmes. Bird Conservation International, 1, 329-334. https://doi.org/10.1017/ S095927090000068X.

Braje, T. J., \& Erlandson, J. M. (2013). Human acceleration of animal and plant extinctions: A late pleistocene, holocene, and anthropocene continuum. Anthropocene, 4, 14-23. https://doi.org/10.1016/j.ancene.2013.08.003.

Cabezas, S., Calvete, C., \& Moreno, S. (2006). Vaccination success and body condition in the European wild rabbit: Applications for conservation strategies. The Journal of Wildlife Management, 70, 1125-1131. https://doi.org/10.2193/0022-541x(2006)70 [1125:vsabci]2.0.co;2.

Ceballos, G., Ehrlich, P. R., Barnosky, A. D., García, A., Pringle, R. M., \& Palmer, T. M. (2015). Accelerated modern human-induced species losses: Entering the sixth mass extinction. Science Advances, 1, 1-5.

Ceballos, G., Ehrlich, P. R., \& Dirzo, R. (2017). Biological annihilation via the ongoing sixth mass extinction signaled by vertebrate population losses and declines. Proceedings of the National Academy of Sciences of the United States of America, 114 E6089-E6096. https://doi.org/10.1073/pnas.1704949114.

Chen, S. N., Ueno, Y., \& Kou, G. H. (1982). A cell line derived from Japanese eel (Anguilla japonica) kidney. In Proceedings of the National Science Council (pp. 93-100).

Chipman, R., Slate, D., Rupprecht, C., \& Mendoza, M. (2008). Downside risk of wildlife translocation. Developments in Biologicals, 131, 223-232.

Council of the European Communities. (2007). Council regulation (EC) no 1100/207 of 18 September 2007 establishing measures for the recovery of the stock of European eel. Official Journal of the European Union, 17-23.

Cresci, A. (2020). A comprehensive hypothesis on the migration of European glass eels (Anguilla anguilla). Biological Reviews, 95, 1273-1286. https://doi.org/10.1111/ brv. 12609.

Dekker, W. (2004). Slipping through our hands Population dynamics of the European eel. Amsterdam University.

Dekker, W. (2003). Worldwide decline of eel resources necessitates immediate action: Québec Declaration of Concern. Fisheries, 28, 28.

Dekker, W. (2000). The fractal geometry of the European eel stock. ICES Journal of Marine Science, 57, 109-121. https://doi.org/10.1006/jmsc.1999.0562.

Dekker, W., \& Beaulaton, L. (2016). Faire mieux que la nature? The history of eel restocking in Europe. Environment and History, 22, 255-300. https://doi.org/ 10.3197/096734016X14574329314407.

Del Mar Gil, M., Palmer, M., Grau, A., \& Balle, S. (2015). Many vulnerable or a few resilient specimens? Finding the optimal for reintroduction/restocking programs. PLoS ONE, 10, 1-21. https://doi.org/10.1371/journal.pone.0138501.

Elie, P., Lecomte Finiger, R., Cantrelle, I., \& Charlon, N. (1982). Définition des limites des différents stades pigmentaires durant la phase civelle d'anguille Anguilla sp. (poisson téléostéen anguilliforme). Vie et milieu, 32, 149-157.

Esteve-Gassent, M. D., Fouz, B., Barrera, R., \& Amaro, C. (2004). Efficacy of oral reimmunisation after immersion vaccination against Vibrio vulnificus in farmed European eels. Aquaculture, 231, 9-22. https://doi.org/10.1016/j. aquaculture.2003.10.006.

Fijan, N., Sulimanović, D., Bearzotti, M., Muzinić, D., Zwillenberg, L. O., Chilmonczyk, S., et al. (1983). Some properties of the Epithelioma papulosum cyprini (EPC) cell line from carp cyprinus carpio. Annales de l'Institut Pasteur Virology, 134, 207-220. https://doi.org/10.1016/S0769-2617(83)80060-4.

Fouz, B., Esteve-Gassent, M. D., Barrera, R., Larsen, J. L., Nielsen, M. E., \& Amaro, C. (2001). Field testing of a vaccine against eel diseases caused by Vibrio vulnificus. Diseases of Aquatic Organisms, 45, 183-189. https://doi.org/10.3354/dao045183.

Fox, J., \& Weisberg, S. (2019). An R Companion to Applied Regression (third edit. ed.). Thousand Oaks, CA: Sage.

Gaughan, D. J. (2001). Disease-translocation across geographic boundaries must be recognized as a risk even in the absence of disease identification: The case with Australian Sardinops. Reviews in Fish Biology and Fisheries, 11, 113-123. https://doi. org/10.1023/A:1015255900836.

Grano-Maldonado, M. I., Gisbert, E., Hirt-Chabbert, J., Paladini, G., Roque, A., Bron, J. E., et al. (2011). An infection of Gyrodactylus anguillae Ergens, 1960 (Monogenea) associated with the mortality of glass eels (Anguilla anguilla L.) on the north-western Mediterranean Sea board of Spain. Veterinary Parasitology, 180, 323-331. https://doi.org/10.1016/j.vetpar.2011.03.004.

Huertas, M., \& Cerdà, J. (2006). Stocking density at early developmental stages affects growth and sex ratio in the European eel (Anguilla anguilla). The Biological Bulletin, 211, 286-296. https://doi.org/10.2307/4134550.

ICES. (2019). Joint EIFAAC/ICES/GFCM Working Group on Eels (WGEEL).

ICES. (2018). Report of the Joint EIFAAC/ICES/GFCM Working Group on Eels (WGEEL), 99 pp. https://doi.org/ICESCM 2017/ACOM:15.

Jacoby, D., \& Gollock, M. (2014). Anguilla anguilla. The IUCN Red List of Threatened Species 2014 [WWW Document]. https://doi.org/e.T60344A45833138.

Jakob, E., Neuhaus, H., Steinhagen, D., Luckhardt, B., \& Hanel, R. (2009). Monitoring of herpesvirus anguillae (HVA) infections in European eel, Anguilla anguilla (L.), in northern Germany. Journal of Fish Diseases, 32, 557-561. https://doi.org/10.1111/ j.1365-2761.2009.01009.x.

Josset, Q., Trancart, T., Mazel, V., Charrier, F., Frotté, L., Acou, A., et al. (2016). Prerelease processes influencing short-term mortality of glass eels in the French eel (Anguilla anguilla, Linnaeus 1758) stocking programme. ICES Journal of Marine Science, 73, 150-157. https://doi.org/10.1093/icesjms/fsv074.

Kirk, R. S. (2003). The impact of Anguillicola crassus on European eels. Fisheries Management and Ecology, 10, 385-394. https://doi.org/10.1111/j.13652400.2003.00355.x. 
Kock, R. A., Woodford, M. H., \& Rossiter, P. B. (2010). Disease risks associated with the translocation of wildlife. OIE Revue Scientifique et Technique, 29, 329-350. https:// doi.org/10.20506/rst.29.2.1980.

Kullmann, B., \& Thiel, R. (2018). Bigger is better in eel stocking measures? Comparison of growth performance, body condition, and benefit-cost ratio of simultaneously stocked glass and farmed eels in a brackish fjord. Fisheries Research, 205, 132-140. https://doi.org/10.1016/j.fishres.2018.04.009.

Kullmann, B., Adamek, M., Steinhagen, D., \& Thiel, R. (2017). Anthropogenic spreading of anguillid herpesvirus 1 by stocking of infected farmed European eels, Anguilla anguilla (L.), in the Schlei fjord in northern Germany. Journal of Fish Diseases, 40, 1695-1706. https://doi.org/10.1111/jfd.12637.

Minterr, B. A., \& Collins, J. P. (2010). Guidelines for reintroductions and other conservation translocations IUCN. Ecologial Applications.

Moriarty, C., \& Dekker, W. (1997). Management of the European eel. Fisheries Bulletin, $15,110$.

Nettles, V. F., Shaddock, J. H., Sikes, R. K., \& Reyes, C. R. (1979). Rabies in translocated raccoons. American Journal of Public Health, 69, 601-602.

Nielsen, M. E., \& Esteve-Gassent, M. D. (2006). The eel immune system: Present knowledge and the need for research. Journal of Fish Diseases, 29, 65-78. https://doi. org/10.1111/j.1365-2761.2006.00695.x.

Nzau Matondo, B., Benitez, J. P., Dierckx, A., Rollin, X., \& Ovidio, M. (2020). An Evaluation of Restocking Practice and Demographic Stock Assessment Methods for Cryptic Juvenile European Eel in Upland Rivers. Sustainability, 12(3). https://doi. org/10.3390/su12031124.

Ogle, D., Wheeler, P., \& Dinno, A. (2019). R package version 0.8.26.9000.

Ottolenghi, F., Silvestri, C., Giordano, P., Lovatelli, A., \& New, M. B. (2004). Capturebased aquaculture: The fattening of eels, groupers, tunas and yellowtails. Rome: FAO. Food and Agriculture Organization of the United Nations.

Ovidio, M., Tarrago-Bes, F., \& Matondo, B. N. (2015). Short-term responses of glass eels transported from UK to small Belgian streams. Annales De Limnologie-International Journal of Limnology, 51, 219-226. https://doi.org/10.1051/limn/2015016.

Pedersen, M. I., \& Rasmussen, G. H. (2015). Yield per recruit from stocking two different sizes of eel (Anguilla anguilla) in the brackish Roskilde Fjord. ICES Journal of Marine Science, 73, 158-164. https://doi.org/10.1093/icesjms/fsv167.

Pedersen, M. I., Jepsen, N., \& Rasmussen, G. (2017). Survival and growth compared between wild and farmed eel stocked in freshwater ponds. Fisheries Research, 194, 112-116. https://doi.org/10.1016/j.fishres.2017.05.013.

Peeler, E. J., Gardiner, R., \& Thrush, M. A. (2004). Qualitative risk assessment of routes of transmission of the exotic fish parasite Gyrodactylus salaris between river catchments in England and Wales. Preventive Veterinary Medicine, 64, 175-189. https://doi.org/10.1016/j.prevetmed.2004.05.005.

Prigge, E., Marohn, L., \& Hanel, R. (2013). Tracking the migratory success of stocked European eels Anguilla anguilla in the Baltic Sea. Journal of Fish Biology, 82, 686-699. https://doi.org/10.1111/jfb.12032.
R Core Team. (2019). R: A language and environment for statistical computing. Vienna, Austria: R Foundation for Statistical Computing.

Roncarati, A., Melotti, P., Mordenti, O., \& Gennari, L. (1997). Influence of stocking density of European eel (Anguilla anguilla, L.) elvers on sex differentiation and zootechnical performances. Journal of Applied Ichthyology, 13, 131-136.

Sandom, C., Faurby, S., Sandel, B., \& Svenning, J. C. (2014). Global late Quaternary megafauna extinctions linked to humans, not climate change. Proceedings of the Royal Society B: Biological Sciences, 281. https://doi.org/10.1098/rspb.2013.3254.

Scheele, B. C., Pasmans, F., Skerratt, L. F., Berger, L., Martel, A., Beukema, W., et al. (2019). Amphibian fungal panzootic causes catastrophic and ongoing loos of biodiversity. Science, 363, 1459-1463.

Seddon, P. J., Armstrong, D. P., \& Maloney, R. F. (2007). Developing the science of reintroduction biology. Conservation Biology, 21, 303-312. https://doi.org/10.1111/ j.1523-1739.2006.00627.x.

Simon, J., \& Dörner, H. (2014). Survival and growth of European eels stocked as glassand farm-sourced eels in five lakes in the first years after stocking. Ecology of Freshwater Fish, 23, 40-48. https://doi.org/10.1111/eff.12050.

Simon, J., Dörner, H., Scott, R. D., Schreckenbach, K., \& Knösche, R. (2013). Comparison of growth and condition of European eels stocked as glass and farm sourced eels in lakes in the first 4 years after stocking. Journal of Applied Ichthyology, 29, 323-330. https://doi.org/10.1111/jai.12078.

Stacey, J. A., Pratt, T. C., Verreault, G., \& Fox, M. G. (2015). A caution for conservation stocking as an approach for recovering Atlantic eels. Aquatic Conservation Marine and Freshwater Ecosystems, 25, 569-580. https://doi.org/10.1002/aqc.2498.

Van Der Hammen, T. (2018). Report Evaluation of glass eel and ongrown eel restocking practices in the Netherlands.

van Ginneken, V. J. T., \& Maes, G. E. (2005). The European eel (Anguilla anguilla, Linnaeus), its lifecycle, evolution and reproduction: A literature review. Reviews in Fish Biology and Fisheries, 15, 367-398. https://doi.org/10.1007/s11160-006-00058.

Westin, L. (1998). The spawning migration of European silver eel (Anguilla anguilla L.) with particular reference to stocked eel in the Baltic. Fisheries Research, 38, 257-270. https://doi.org/10.1016/S0165-7836(98)00162-3.

Wickström, H., \& Sjöberg, N. B. (2014). Traceability of stocked eels - the Swedish approach. Ecology of Freshwater Fish, 23, 33-39. https://doi.org/10.1111/eff.12053.

Wickström, H., Clevestam, P., \& Höglund, J. (1998). The spreading of Anguillicola crassus in freshwater lakes in Sweden. Bulletin français de la pêche et de la pisciculture, 349, 215-221.

Wolf, K., Gravell, M., \& Malsberger, R. G. (1966). Lymphocystis virus: Isolation and propagation in centrarchid fish cell lines. Science, 151, 1004 LP-1005. https://doi. org/10.1126/science.151.3713.1004. 